\title{
CREATINA: ESTRATÉGIA ERGOGÊNICA NO MEIO ESPORTIVO. UMA BREVE REVISÃO
}

\author{
CREATINE: ERGOGENIC STRATEGY IN THE SPORTS FIELD. A BRIEF REVIEW \\ Mariana Santos Rodrigues Leite ${ }^{a^{*}}$, Stéphane Castellar Sousa ${ }^{b^{*}}$, \\ Fernanda Mendonça Silva ${ }^{\mathrm{c}^{*}}$, João Carlos Marins Bouzas ${ }^{\mathrm{d}^{*}}$ \\ amariana.leitenut@yahoo.com.br, btecastellar@yahoo.com.br, cfernandam@ymail.com, djcbouzas@ufv.br \\ *Universidade Federal de Viçosa - Viçosa (MG), Brasil
}

Data de entrada do artigo: 11/02/2014

Data de aceite do artigo: 15/08/2014

\section{RESUMO}

Introduçáo: Os suplementos alimentares têm sido muito utilizados por atletas e praticantes de atividade física para melhoria da performance e para fins estéticos. Entre os mais populares, encontra-se a creatina, cujo uso está associado, entre outros, a ganho de força e massa muscular. Objetivo: Investigar as formas de comercialização, as prevalências de consumo e os efeitos do uso de creatina. Materiais e métodos: Utilizaram-se as bases de pesquisa on-line PubMed/Medline e Scielo para detectar artigos disponíveis e publicados em língua portuguesa e inglesa no período de 2007 a 2013. As referências citadas nesses artigos também foram revisadas, além de sites de empresas que comercializam o produto. Foram incluídos estudos com seres humanos maiores de idade e saudáveis. Resultado: A creatina é comercializada sob diversas formas e estados físicos, sendo mais comum encontrá-la em pó e adicionada de outras substâncias, como carboidratos e proteínas. A prevalência de consumo varia de $10 \%$ a $89 \%$ em estudos recentes, e o protocolo de suplementaçáo prevê uma fase de sobrecarga, seguida da fase de manutenção. A renovação mais rápida de energia, o ganho de força e o aumento da massa corporal total são os efeitos ergogênicos mais evidentes relacionados ao uso da creatina. Outros possíveis benefícios, tais como redução da acidez muscular e termorregulação, são bastante controversos. Efeitos nocivos não foram comprovados, entretanto, são necessários mais estudos. Conclusáo: As evidências apontam que a creatina pode ser um recurso ergogênico eficiente e relativamente seguro, desde que o seu uso seja orientado por profissional habilitado.

Palavras-chave: creatina; suplementação alimentar; exercício; hipertrofia; força muscular.

\section{ABSTRACT}

Introduction: The dietary supplements have been used by athletes and physically active people to improve performance and for aesthetic purposes. One of the most popular supplements is creatine, which is widely used to increase strength and fat free mass. Objective: To investigate the commercialization forms, consumption prevalence and the effects of creatine intake. Materials and methods: The online research bases as PubMed/Medline and Scielo were used to collect articles in Portuguese or English, on the period of 2007 to 2013. The references were revised, as well as sites of companies which market the product. Researches with healthy and of age humans were included. Results: The creatine is commercialized in different ways and physical states, and it is more common to find it in the form of powder or added to other substances, such as carbohydrates and proteins. The prevalence of consumption varies between 10 to 89 percent in recent studies and the supplementation protocol includes an overload phase, followed by a maintenance phase. The fast renewal of energy, strength gain and the increase of body mass are the most remarkable ergogenic effects related to creatine consumption. Other possible benefits, such as muscular 
acidity and thermoregulation, are very controversial. Adverse effects were not comproved, but more studies are necessary. Conclusion: The evidences indicate thar creatine is an efficient and safe ergogenic supplement, as long as it is used according to professional guidelines.

Keywords: Creatine. Supplementary feeding. Exercise. Hypertrophy. Muscle strength.

\section{Introdução}

Um adequado aporte nutricional possibilita equilibrar necessidades calóricas, de macronutrientes, vitaminas e minerais, fundamentais para o treinamento e a competição. Entretanto, em certos casos, pode ser necessário o uso de suplementos nutricionais de acordo com a modalidade e as necessidades específicas do atleta ou do momento da periodizaçãa ${ }^{1}$.

Certos suplementos nutricionais têm sido associados a efeitos ergogênicos tais como aumento de massa corporal total e de massa magra, aumento de força muscular e de resistência e redução da gordura corporal. Esses recursos vêm sendo amplamente procurados por atletas e indivíduos praticantes de atividade física para melhoria do desempenho físico, para complementação da dieta ou mesmo para fins estéticos ${ }^{2}$.

Alguns estudos sobre o levantamento de recursos ergogênicos apontaram que, entre os suplementos mais populares, encontram-se: a) maltodextrina; b) proteína hidrolisada do soro de leite, conhecido como whey protein; c) aminoácidos de cadeia ramificada (BCAAs); d) creatina $(\mathrm{Cr})^{2,3,4}$. Esta última tem sido relacionada à melhora do rendimento físico, principalmente devido ao aumento da força muscular, da massa corporal e da tolerância ao exercício ${ }^{2,5,6}$.

A Cr pode ser obtida através de duas fontes: endógena, em que cerca de 1 grama é sintetizado por dia utilizando-se os aminoácidos arginina, glicina e metionina; exógena, através do consumo de carnes vermelhas, aves, peixes e alguns vegetais. Estima-se que, em um homem de 70 quilos, a necessidade diária de $\mathrm{Cr}$ seja de 2 gramas, sendo que aproximadamente metade desse valor é obtida através da dieta ${ }^{7,8}$.

A Cr sintetizada é transportada pelo sangue para os tecidos musculares, nos quais se encontra $95 \%$ do total corporal, sendo que, desse total, aproximadamente $60 \%$ encontra-se na forma fosforilada e $40 \%$ na forma livre. Os 5\% restantes do pool orgânico encontram-se distribuídos no cérebro, fígado, rim e testículos ${ }^{5}$.

O papel básico da $\mathrm{Cr}$ no organismo está relacionado ao metabolismo energético, sendo assim, uma deficiência nos estoques corporais pode limitar o desempenho físico, principalmente em atletas de modalidades que envolvem força explosiva, como o levantamento de peso olímpico, o futebol e o basquetebol, ou o ganho de massa muscular, em modalidades como o fisiculturismo ${ }^{7,9}$.

Considerando que a creatina tem sido muito utilizada no meio esportivo e as evidências sinalizam possíveis benefícios quanto ao seu consumo como recurso ergogênico, o objetivo deste estudo é investigar as formas de comercialização do produto, a prevalência de consumo e as evidências quanto aos mecanismos de ação e efeitos da suplementação.

\section{Materiais e métodos}

Foi realizada uma revisão sistemática da literatura, nas bases de pesquisa on-line PubMed/Medline e Scielo, utilizando-se uma combinação das seguintes palavraschave: "creatine" + "body composition", "creatine" + "water retention", "creatine and thermoregulation" + "creatine supplementation".

Como critério de inclusão, foram considerados os artigos disponíveis e publicados nas línguas portuguesa e inglesa, no período compreendido entre 2007 e julho de 2013, realizados com seres humanos maiores de idade e saudáveis, conforme exposto na Tabela 1. As referências bibliográficas dos artigos identificados pela pesquisa eletrônica também foram revisadas para detectar estudos adicionais, além de sites de empresas que comercializam o produto.

Tabela 1: Quantificação dos filtros realizados no Pubmed utilizando palavras-chave.

\begin{tabular}{ccccc}
\hline & $\begin{array}{c}\text { "Creatine" + "body } \\
\text { composition" }\end{array}$ & $\begin{array}{c}\text { "Creatine" + "water } \\
\text { retention" }\end{array}$ & $\begin{array}{c}\text { "Creatine" + } \\
\text { "thermoregulation" }\end{array}$ & $\begin{array}{c}\text { "Creatine } \\
\text { supplementation" }\end{array}$ \\
\hline Janeiro de 2007 a julho de $\mathbf{2 0 1 3}$ & 96 & 49 & 587 & 6 \\
Humanos & 58 & 26 & 363 & 3 \\
Adultos & 24 & 10 & 146 & 1 \\
Texto completo & 24 & 10 & 141 & 1 \\
\hline
\end{tabular}




\section{Desenvolvimento}

\section{Breve Histórico}

Michel Chevreu foi o primeiro a relatar a creatina como um componente natural dos músculos contráteis, em 1832. Porém, somente em 1847 essa teoria foi confirmada por Justus Liebig, em um estudo que relatou que animais selvagens possuíam maior quantidade de $\mathrm{Cr}$ quando comparados a animais criados em cativeiro, concluindo que o acúmulo desse constituinte seria resultado do trabalho muscular. Em 1880, foi descoberta a creatinina, a qual estava presente na urina de humanos, e os autores passaram a especular se esta era derivada da $\mathrm{Cr}^{10,11,12}$.

No início do século XX, estudos mostraram que nem toda creatina ingerida era excretada pela urina, levando à constatação de que o organismo armazenava uma parte. A partir disso, surgiram novas descobertas, como a influência da ingestáo da $\mathrm{Cr}$ sobre a composição muscular, conteúdo total no organismo humano e existência de outras formas deste composto, como, por exemplo, a fosfocreatina (PCr). Mais recentemente, estudos investigam sobre o seu potencial uso como recurso ergogênico ${ }^{10,11,13}$.

\section{Comercialização da Creatina}

A Cr pode ser encontrada sob diversas formas, sendo elas: monoidrato de creatina $(88 \%$ creatina e $12 \%$ água); creatina anidro (creatina em que a molécula de água foi removida a fim de aumentar a concentração); sais, como piruvato de creatina, citrato de creatina, creatina malato, creatina fosfato, creatina magnésio; Kre Alkalyn (creatina com bicarbonato de sódio); éster, como creatina etil-éster. $\mathrm{O}$ monoidrato de creatina é a forma mais comum disponível no mercado, sendo, portanto, a mais utilizada nas pesquisas ${ }^{14}$.

A comercialização de $\mathrm{Cr}$ é feita sob os mais variados estados físicos: pó, gel, líquido, barras, tabletes e cápsulas. Alguns desses produtos misturam o monoidrato de creatina a outros compostos, como carboidratos e proteínas, cuja adição tem sido relacionada a uma maior retenção de Cr pelo músculo. Aminoácidos, vitaminas, extratos herbais e fitoquímicos também podem ser encontrados nas formulaçóes. O Quadro 1 apresenta algumas marcas comercializadas no Brasil com registro na Agência Nacional de Vigilância Sanitária (Anivisa).

Entre as formas de apresentação do suplemento de Cr, a mais comum é em pó, encontrada em nove das dez marcas citadas, e a menos comum é a líquida, encontrada somente na marca Body Action.

\section{Prevalência de Consumo}

Vários estudos têm observado alta prevalência de uso da creatina como recurso ergogênico, sendo que a maioria dos consumidores a utiliza sem a orientação do médico ou nutricionista, que são os profissionais habilitados para este fim. A Tabela 2 mostra a prevalência

Quadro 1: Formas de comercialização e ingredientes de algumas marcas de creatina vendidas no Brasil.

\begin{tabular}{|c|c|c|}
\hline Marca & Formas de comercializaçáo* & Ingredientes* \\
\hline Arnold Nutrition ${ }^{\circ}$ & Pó, cápsula e tablete & Em ambas as formas, tem somente a creatina como ingrediente \\
\hline Atletika & Pó e tablete & $\begin{array}{c}\text { Em pó, pode-se encontrar com adiçáo de outros ingredientes, como a } \\
\text { maltodextrina }\end{array}$ \\
\hline Body Action & Pó, tablete e líquido & $\mathrm{Na}$ forma líquida, com adição de trealose \\
\hline Integralmédica & Pó, cápsula e tablete & $\begin{array}{l}\text { Em pó, com adição de ingredientes como a D-ribose; em tablete, encontra-se } \\
\text { em sua formulação a lactose e o amido de milho }\end{array}$ \\
\hline Max Titanium & Pó e cápsula & Em ambas as formas, tem somente a creatina como ingrediente \\
\hline Midway & Pó, cápsula e tablete & $\begin{array}{l}\text { Em pó, pode ter adição de maltodextrina e cloreto de sódio; em cápsulas, } \\
\text { encontra-se também acrescida de amido de milho; na forma de tablete, de } \\
\text { amido de milho e lactose }\end{array}$ \\
\hline Neo Nutri & Cápsula e tablete & $\begin{array}{l}\text { Na forma de tablete, encontra-se em sua formulação o carbonato de cálcio } \\
\text { mineral }\end{array}$ \\
\hline Nutrilatina & Pó e cápsula & Somente creatina mono-hidratada \\
\hline Probiótica & Pó e cápsula & $\begin{array}{c}\text { Na forma em pó, pode-se encontrar também adição de outros ingredientes, } \\
\text { como a maltodextrina e D-ribose e dextrose }\end{array}$ \\
\hline Universal Nutrition $^{\odot}$ & Pó, cápsula e tablete. & $\begin{array}{l}\text { Em tablete, com adição de sacarose, dextrose, maltodextrina e óleo de palma; } \\
\text { em cápsulas, com adição de carbonato de potássio e bicarbonato de sódio }\end{array}$ \\
\hline
\end{tabular}

* As formas de comercialização e os ingredientes foram obtidos nos sites dos respectivos fabricantes. 
de consumo da creatina em estudos realizados com praticantes de atividade física em diferentes cidades do Brasil. Em todos os artigos citados, a $\mathrm{Cr}$ aparece como um dos recursos ergogênicos mais utilizados.

$\mathrm{O}$ protocolo de suplementação de $\mathrm{Cr}$ é dividido em duas etapas: na primeira, chamada de "fase de sobrecarga", há administração de uma dose maior de creatina; na segunda, chamada de "fase de manutenção", administram-se doses menores do suplemento. $\mathrm{O}$ protocolo mais utilizado consiste na ingestão diária de 20 a 30 g de creatina, dividida em 4 doses iguais de 5 a $7 \mathrm{~g}$ em $250 \mathrm{ml}$ de líquido para o período de sobrecarga,

Tabela 2: Prevalência de consumo de creatina em diferentes estudos no Brasil.

\begin{tabular}{|c|c|c|c|c|}
\hline Estudo & Local & Amostra & $\mathbf{n}$ & $\begin{array}{l}\text { Prevalência } \\
(\%)\end{array}$ \\
\hline Pereira $(2014)^{2}$ & Barra do Piraí (RJ) & $\begin{array}{l}\text { Alunos de academias } \\
18-58 \text { anos }\end{array}$ & 101 & 42,1 \\
\hline Silva e Marins $(2013)^{3}$ & Viçosa (MG) & $\begin{array}{l}\text { Praticantes de modalidades esportivas olímpicas } \\
\qquad 18-55 \text { anos }\end{array}$ & 351 & 43,5 \\
\hline $\begin{array}{l}\text { Andrade, Braz, Nunes, } \\
\text { Velutto e Mendes }(2012)^{4}\end{array}$ & São Paulo (SP) & $\begin{array}{l}\text { Clientes de uma clínica de nutrição esportiva } \\
\text { 20-56 anos }\end{array}$ & 60 & 50 \\
\hline Alencar et al. $(2010)^{38}$ & Ouricuri (PE) & Homens, praticantes de musculação $15-35$ anos & 70 & 27 \\
\hline Gomes $(2010)^{39}$ & Coimbra (MG) & $\begin{array}{l}\text { Frequentadores de ginásios e health clubs } \\
\qquad 16-61 \text { anos }\end{array}$ & 374 & 18 \\
\hline $\begin{array}{l}\text { Pedrosa, Silva e Pinho } \\
\qquad(2010)^{40}\end{array}$ & Porto Velho (RO) & Praticantes de musculação de academias > 15 anos & 191 & 10 \\
\hline $\begin{array}{l}\text { Domingues e Marins } \\
\qquad(2007)^{41}\end{array}$ & $\begin{array}{l}\text { Belo Horizonte } \\
\quad(\mathrm{MG})\end{array}$ & $\begin{array}{l}\text { Praticantes de musculaçáo } \\
15-70 \text { anos }\end{array}$ & 200 & 89 \\
\hline Pimenta e Lopes $(2007)^{37}$ & Cascavel (PR) & $\begin{array}{l}\text { Alunos que frequentavam a academia havia mais de } 3 \text { meses } \\
\qquad 27 \pm 7,2 \text { anos }\end{array}$ & 94 & 24 \\
\hline
\end{tabular}

seguida de uma fase de manutenção, com ingestão de 2 a $5 \mathrm{~g} / \mathrm{dia}^{15}$. Já o Consenso do Colégio Americano de Medicina Esportiva propóe que um consumo de $0,3 \mathrm{~g} /$ $\mathrm{kg}$ de peso por dia durante um período de 30 dias seria suficiente para elevar as concentraçóes de creatina nos músculos ${ }^{16}$.

Quando baseado no peso corporal, o protocolo mais comumente utilizado é o proposto por Hultman et al. ${ }^{17}$ , que consiste na suplementação de $0,3 \mathrm{~g} / \mathrm{kg}$ de peso por dia, dividida em 4 doses diárias, durante 5 a 6 dias, seguida por uma fase de manutenção de $0,03 \mathrm{~g} / \mathrm{kg}$ de peso por dia, pelo mesmo período.

A maior parte dos rótulos dos produtos citados no Quadro 1 sugeriu a ingestáo de aproximadamente $3 \mathrm{~g}$ por dia, diluídos em 200 a $250 \mathrm{ml}$ de líquido, como água, sucos e bebidas carboidratadas.

\section{Efeitos Ergogênicos}

Uma série de efeitos ergogênicos tem sido frequentemente associada ao consumo de creatina. A seguir, serão apresentados com detalhes os mais discutidos na base documental consultada.

\section{A) Renovação mais Rápida de ATP}

O trifosfato de adenosina (ATP) se encontra armazenado nas células em quantidade limitada, fazendo-se necessária a ressíntese contínua dessa molécula. A regeneração do ATP ocorre pela transferência do grupo fosfato da PCr para a molécula de difosfato de adenosina (ADP), em uma reação reversível catalisada pela enzima creatina quinase. Essa reação de quebra da $\mathrm{PCr}$ ocorre no local de utilização da energia, a miosina. A Cr livre é levada para a membrana mitocondrial da célula muscular, onde é fosforilada novamente através da energia da quebra do ATP em ADP, o que faz da PCr um reservatório de energia ${ }^{7}$.

A suplementação com creatina poderia aumentar a concentração corporal total de $\mathrm{Cr}$, possivelmente facilitando a geração intramuscular de creatina fosfato e a subsequente formação de ATP, em especial nas fibras musculares de contração rápida, aumentando, assim, a capacidade atlética anaeróbica alática, componente fundamental em provas de curta duração e alta intensidade ${ }^{18}$. 
Balsom et al. ${ }^{18}$ relataram aumento de até $25 \%$ nos estoques intramusculares de $\mathrm{Cr}$ total após suplementaçáo de $20 \mathrm{~g}$ de $\mathrm{Cr}$ durante 5 dias $^{18}$. Em estudo realizado por Greenhaff et al. ${ }^{19}$, observou-se que a $\mathrm{Cr}$ livre tem papel fundamental no controle da ressíntese de $\mathrm{PCr}$ e ATP e que a aceleração da ressíntese de fosfocreatina após o exercício aumenta a capacidade muscular contrátil, mantendo o turnover de ATP durante o exercício subsequente $^{19}$.

Dessa forma, existe uma boa fundamentação para considerar que o consumo de creatina pode ter um efeito ergogênico ao aprimorar a capacidade energética do atleta em provas de componente anaeróbico alático, como, por exemplo, provas de salto, arremesso e lançamento no atletismo, no levantamento de peso olímpico, provas de velocidade na natação, ou modalidades coletivas como o futebol. Em indivíduos vegetarianos, a suplementação com $\mathrm{Cr}$ também pode ser benéfica, uma vez que estes tendem a ter uma reserva menor desse composto, geralmente encontrado em produtos de origem animal.

B) Acidez Muscular Reduzida

Tabela 3: Suplementação de creatina e sua influência sobre a massa corporal.

\begin{tabular}{|c|c|c|c|c|}
\hline 1 & Amostra & Dosagem & Tempo & Resultados \\
\hline Chilibeck, Magnus e Anderson (2007) ${ }^{42}$ & $\mathrm{~N}=18(\mathrm{H})$ & $0,1 \mathrm{~g} / \mathrm{kg} / \mathrm{d}$ & $8 \mathrm{sem}$ & $\leftarrow \mathrm{MCT}$ \\
\hline Cribb, Williams, Stathis, Carey e Hayes $(2007)^{43}$ & $\mathrm{~N}=33$ & $\begin{array}{l}0,3 \mathrm{~g} / \mathrm{kg} / \mathrm{d} \text { por } 1 \mathrm{sem} \\
0,1 \mathrm{~g} / \mathrm{kg} / \mathrm{d} \text { por } 10 \mathrm{sem}\end{array}$ & $11 \mathrm{sem}$ & $\uparrow \mathrm{MCT}$ \\
\hline Donatto, Prestes, Silva, Capra e Navarro $(2007)^{31}$ & $\begin{array}{l}N=10(\mathrm{H}) \\
18-25 \text { anos }\end{array}$ & $20 \mathrm{~g} / \mathrm{d}$ por $5 \mathrm{~d}$ & $5 \mathrm{~d}$ & $\begin{array}{l}\leftarrow \mathrm{MCT} \\
\leftarrow \mathrm{MM}\end{array}$ \\
\hline $\begin{array}{l}\text { Souza Júnior, Dubas, Pereira e De Oliveira } \\
\qquad(2007)^{44}\end{array}$ & $\begin{array}{l}\mathrm{N}=18(\mathrm{H}) \\
19-25 \text { anos }\end{array}$ & $\begin{array}{c}30 \mathrm{~g} / \mathrm{d} \text { na } 3^{\mathrm{a}} \text { sem } \\
5 \mathrm{~g} / \mathrm{d} \text { da } 4^{\mathrm{a}} \text { a } 8^{\mathrm{a}} \text { sem }\end{array}$ & $8 \mathrm{sem}$ & $\uparrow \mathrm{MCT}$ \\
\hline $\begin{array}{l}\text { Hunger, Prestes, Leite, Pereira e Cavaglieri } \\
\qquad(2009)^{29}\end{array}$ & $\begin{array}{l}\underline{N}=27(\mathrm{H}) \\
\mathrm{X}=23 \text { anos }\end{array}$ & $\begin{array}{c}20 \mathrm{~g} / \mathrm{d} \text { por } 5 \mathrm{~d} \\
5 \mathrm{~g} / \mathrm{d} \text { no restante dos dias }\end{array}$ & 8 sem & $\leftarrow \mathrm{MCT}$ \\
\hline $\begin{array}{l}\text { Batista, Bravo, Costa, De Paula, Araújo e Cunha. } \\
\qquad(2010)^{30}\end{array}$ & $\mathrm{~N}=20(\mathrm{H})$ & $\begin{array}{c}20 \mathrm{~g} / \mathrm{d} \text { por } 6 \mathrm{~d} \mathrm{e} \\
5 \mathrm{~g} / \mathrm{d} \text { no restante dos dias }\end{array}$ & $3 \mathrm{sem}$ & $\uparrow \mathrm{MCT}$ \\
\hline
\end{tabular}

Abreviaçōes e símbolos: sem $=$ semana(s); $\mathrm{d}=\operatorname{dia}(\mathrm{s}) ; \leftarrow \rightarrow=$ sem alteraçôes estatisticamente significativas; $\uparrow=$ aumento estatisticamente significante; ${ }^{*}=$ sem alteraçōes estatisticamente significativas em relação ao grupo controle; $\mathrm{H}$ = homens; $\mathrm{MCT}$ =Massa Corporal Total; MM = Massa Magra.

A PCr é responsável por cerca de 30\% da capacidade total do tamponamento muscular. Na reação de ressíntese do ATP a partir de ADP e PCr, há consumo de um íon $\mathrm{H}^{+}$. Sabe-se que o aumento desses íons, juntamente com a reduçáo do $\mathrm{pH}$ muscular, leva ao início do processo de fadiga. Assim, a suplementação de creatina reduziria a acidez muscular, prevenindo o acúmulo de ácido láctico no músculo ${ }^{10}$.

Greenhaff et al. ${ }^{19}$, através de biópsia do músculo vasto lateral de 8 indivíduos suplementados com $\mathrm{Cr}$, analisaram $\mathrm{Cr}$ muscular, $\mathrm{PCr}$ e concentração de lactato e encontraram aumento na concentração de $\mathrm{Cr}$ e ressíntese de $\mathrm{PCr}$ durante a recuperação, mas não observaram alteraçóes sobre os níveis de lactato ${ }^{19}$, o que corrobora estudo de Mujica et al. ${ }^{20}$. Entretanto, em estudo mais recente, Yquel $e t a l^{21}$, encontraram níveis de ácido lático mais baixos após suplementação com creatina ${ }^{21}$.

Tendo em vista a dificuldade metodológica de estudo sobre essa adaptação, esse benefício deve ser considerado com cautela, devendo haver mais estudos para sua confirmação.

\section{C) Aumento da massa corporal}

O aumento da massa corporal tem sido considerado um dos fatores mais evidentes decorrentes do consumo de creatina. A Tabela 3 apresenta os resultados de alguns estudos realizados nos últimos sete anos.

Os mecanismos fisiológicos que poderiam explicar o aumento da massa corporal não são totalmente esclarecidos. Uma das teorias afirma que esse aumento seria devido à retenção hídrica. Outra sugere que ocorre aumento da síntese proteica e/ou redução da degradação de proteínas devido à suplementaçẫo com creatina ${ }^{22}$.

$\mathrm{O}$ aumento da massa corporal pode ser interessante para atletas que necessitam dessa adaptação, como, por exemplo, certos jogadores de futebol, principalmente de categoria de base. Contudo, para atletas de lutas e levantamento de peso olímpico, seu consumo deve ser feito de forma criteriosa, pois poderá modificar a faixa de categoria de peso a que pertencem.

D) Retenção Hídrica 
Para Hultman et al. ${ }^{17} \mathrm{o}$ aumento da concentração de $\mathrm{Cr}$ intracelular poderia induzir um influxo de água para dentro da célula, resultando em retenção hídrica e consequente aumento da $\mathrm{MC}^{17}$.

Um dos primeiros estudos que analisou as mudanças relativas no volume de fluido corporal durante a suplementação de $\mathrm{Cr}$ foi realizado por Ziegenfuss, et al. ${ }^{23}$. Nesta pesquisa, 10 homens treinados consumiram 0,07 $\mathrm{g}$ de creatina por quilo de massa livre de gordura durante 3 dias. O consumo de $\mathrm{Cr}$ aumentou a água corporal total e intracelular, e os autores concluíram que a suplementação pode conduzir a uma mudança de equilíbrio de fluidos. Porém, não foi avaliado o conteúdo de creatina muscular, não sendo possível, portanto, afirmar se essas alteraçôes de fluidos são devidas ao aumento das concentraçóes de $\mathrm{Cr}$.

Kreider et al. examinaram os efeitos do consumo de Cr sobre a massa e a composição corporal e encontraram um aumento da $\mathrm{MC}$, muito maior, no grupo que recebeu suplementaçấo de Cr por 28 dias, quando comparado ao grupo placebo ${ }^{12}$. Não se observou mudança no total de água corporal, sugerindo que o aumento da massa não tem relação com a retenção hídrica. A Tabela 4 apresenta os resultados de alguns estudos publicados nos últimos anos em relação à retenção hídrica.

Apesar do estudo de Branch et al. ter observado que não ocorre diferença significativa em relação ao conteúdo de água corporal após suplementação de $\mathrm{Cr}^{24} \mathrm{e}$ Jagim et al. registrarem reduçãa ${ }^{25}$, a maior parte dos trabalhos sinaliza aumento. Essa adaptação proporcionaria um maior volume corporal, sendo interessante para as pessoas que têm esse objetivo estético.

\section{E) Aumento da Massa Magra}

De acordo com Tarnopolsky, o aumento da massa corporal devido à suplementaçáo com creatina ocorre graças à retenção hídrica ${ }^{8}$. Porém, quando o consumo é combinado com exercícios de resistência, há um aumento de massa magra. Tal resultado pode ser ocasionado por um aumento na capacidade energética alática, o que permitiria maior carga de treino e, consequentemente, maior hipertrofia.

Estudos relatam que o aumento da massa corporal se dá apenas através da síntese proteica ${ }^{9,26}$, haja vista que a Cr é apontada como estimuladora da biossíntese de proteínas miofibrilares e da captaçáo de aminoácidos pelas proteínas contráteis.

Segundo Souza Júnior et al., a creatina é captada pelo músculo via estimulação de insulina e por transporte sódio dependente ${ }^{27}$. Esse processo gera gradiente de sódio e de aminoácidos através da membrana celular, que, por sua vez, drena a água para a célula. Em longo prazo, o aumento da hidratação celular pode ser um sinal anabólico que aumenta a retenção de nitrogênio ${ }^{28}$.

Jagim et al. estudaram os efeitos da suplementação de creatina mono-hidratada em 36 participantes treinados, durante 28 dias $^{25}$. Foi encontrado que a massa corporal total e a massa magra aumentaram em todos os grupos ao longo do tempo de estudo. Náo houve reduçáo significativa do percentual de gordura corporal em nenhum dos grupos, e o total de água corporal diminuiu significativamente em todos os grupos.

Dessa forma, essa adaptaçáo pode ser interessante em atletas jovens que precisam ganhar massa muscular, principalmente fisiculturistas e pessoas que possuem objetivos estéticos voltados para hipertrofia. Entretanto, para atletas para os quais o aumento do peso corporal não é interessante, como corredores, o consumo do produto deve ser avaliado com cautela.

Tabela 4: Suplementação de creatina e sua influência sobre a retenção hídrica

\begin{tabular}{|c|c|c|c|c|}
\hline Estudos & Amostra & Dosagem & Tempo & Resultados \\
\hline $\begin{array}{l}\text { Branch, Schuarz e } \\
\text { Lunen }(2007)^{24}\end{array}$ & 7 ciclistas e triatletas & $\begin{array}{l}\text { Grupo Cr: } 20 \mathrm{~g} / \mathrm{d} \text { por } 5 \mathrm{~d} \\
\text { Placebo: } 20 \mathrm{~g} / \mathrm{d} \text { dextrose }\end{array}$ & $28 \mathrm{~d}$ & $\begin{array}{c}\leftarrow \rightarrow \text { água corporal total. } \\
\text { Sem diferença na desidratação } \\
\text { pós-exercício. }\end{array}$ \\
\hline $\begin{array}{l}\text { Easton, Turner e } \\
\text { Pitsiladis }(2007)^{45}\end{array}$ & $\begin{array}{c}24 \text { homens com treinamento } \\
\text { de resistência }\end{array}$ & $\begin{array}{c}\text { Grupo Cr: } 10 \mathrm{~g} \\
\text { Placebo: } 85 \mathrm{~g} \text { glucose } \\
+1 \mathrm{~g} / \mathrm{kg} \text { de glicerol ou } \\
\text { placebo }\end{array}$ & $1 \mathrm{sem}$ & $\begin{array}{l}\text { 个água corporal total, água } \\
\text { intracelular e extracelular. } \\
\text { Sem diferenças na perda pelo } \\
\text { suor. }\end{array}$ \\
\hline $\begin{array}{l}\text { Wright, Grandiean } \\
\text { e Pascoe }(2007)^{33}\end{array}$ & $\begin{array}{l}10 \text { homens fisicamente ativos } \\
\text { aclimatados ao calor }\end{array}$ & $\begin{array}{c}\text { Grupo Cr: } 20 \mathrm{~g} / \mathrm{d} \text { por } 6 \mathrm{~d} \\
\text { Placebo: } 20 \mathrm{~g} \\
\text { maltodextrina/d }\end{array}$ & $6 \mathrm{~d}$ & $\begin{array}{l}\uparrow \text { água corporal total ( } 1,3 \mathrm{~kg}) \text {. } \\
\text { Sem diferenças na perda pelo } \\
\text { suor. }\end{array}$ \\
\hline $\begin{array}{l}\text { Jagim et al. } \\
(2012)^{25}\end{array}$ & 36 homens treinados & $\begin{array}{c}20 \mathrm{~g} / \mathrm{d} \text { por } 7 \mathrm{~d} \text { seguido de } 5 \\
\mathrm{~g} / \text { dia por } 21 \mathrm{~d}\end{array}$ & $28 \mathrm{~d}$ & $\downarrow$ água corporal total \\
\hline
\end{tabular}

Abreviaçốes e símbolos: sem $=$ semana(s); $\mathrm{d}=\mathrm{dia}(s) ; \leftarrow \rightarrow=$ sem alteraçốes estatisticamente significativas; $\uparrow=$ aumento estatisticamente significante; ${ }^{*}=$ sem alteraçôes estatisticamente significativas em relação ao grupo controle. 


\section{F) Ganho de Força}

Um possível ganho de força decorrente do consumo de $\mathrm{Cr}$ seria decorrente do aumento das reservas intramusculares de fosfocreatina, em curto prazo, e da hipertrofia muscular, em longo prazo. Hunger et al. analisaram os efeitos da suplementação de Cr e treinamento de força periodizado sobre a composiçáo corporal e força máxima dinâmica durante 8 semanas, em 27 voluntários ${ }^{29}$. Foi observado aumento percentual na massa corporal total e massa magra, porém sem diferença estatística e aumento significativo na força máxima dinâmica em todos os grupos de estudo.

Batista et al. avaliaram 20 indivíduos do sexo masculino, praticantes do treinamento de força, durante 3 semanas, com o objetivo de verificar o efeito da suplementação de Cr sobre as variáveis antropométricas e a resultante de força máxima ${ }^{30}$. Os autores observaram que o grupo suplementado apresentou ganhos estatisticamente significativos na massa corporal, perimetria do braço e antebraço direito, tórax, além de melhores resultados nos testes de força máxima em todos os exercícios analisados.

Já Donatto et al., analisando os efeitos da suplementação aguda de $\mathrm{Cr}$ sobre a composição corporal e sua influência no ganho de força em 10 indivíduos do sexo masculino integrados em um programa de exercícios físicos, encontraram aumento não significativo no peso e massa muscular e na produçáo de força, concluindo que o consumo de $\mathrm{Cr}$ não exerce efeito sobre a composição corporal e não promove ganho de força ${ }^{31}$.

Os resultados das pesquisas são controversos sobre esse possível efeito ergogênico, devendo ser ampliados os modelos de estudo sobre essa possível adaptação positiva decorrente do consumo de creatina.

\section{G) Termorregulação}

Segundo Dalbo et al., a creatina poderia ter ação positiva sobre a termorregulação, pois aumentaria as reservas hídricas corporais, tornando mais difícil atingir níveis críticos de desidratação em exercícios de longa duraçấo em ambiente de calor ${ }^{32}$. Contudo, alguns estudos não encontraram tal efeito ${ }^{24,33,34}$.

Mendel et al., com o objetivo de verificar a hipótese de a creatina interferir nas mudanças de fluidos corporais durante o exercício em ambientes quentes, analisaram 16 indivíduos em um teste de consumo máximo de oxigênio ${ }^{34}$. Verificou-se que as temperaturas corporal e retal foram menores nos grupos suplementado e placebo, levando os autores a concluírem que a suplementação com $\mathrm{Cr}$ em curto prazo não tem efeito sobre a termorregulação.

Corroborando este resultado, Wright et al. observaram o efeito de 6 dias de suplementação de creatina sobre a termorregulação durante a performance de sprint em bicicleta ergométrica, em um ambiente a $35^{\circ} \mathrm{C}$ e umidade relativa de $60 \%{ }^{33}$. Quando comparado com as medidas pré-exercício, o exercício no calor produziu aumento significativo na temperatura interior, perda de água corporal e mudança relativa do volume do plasma, porém nenhuma dessas mudanças foi significativa quando comparada às do grupo placebo.

Branch et al. analisaram a resposta da suplementação de $\mathrm{Cr}$ sobre a termorregulação em homens ciclistas e triatletas. Os autores concluíram que a suplementação com $\mathrm{Cr}$ reduz a perda de volume plasmático durante 1 hora de exercício em ambiente de calor, mas parece não mudar a resposta da termorregulaçãa ${ }^{24}$.

Em uma revisão, que teve como critérios de inclusão estudos experimentais com homens e mulheres fisicamente ativos, Lopez et al. concluíram que não existem evidências substanciais que comprovem que a suplementação com creatina melhora a capacidade do corpo de dissipar o calor ou o balanço de água corporal, quando doses apropriadas são consumidas ${ }^{35}$.

Diante disso, conclui-se que são necessários mais estudos para a comprovaçáo de tal efeito, principalmente em provas de longa duração, como maratona, ciclismo, mountain bike e provas de aventura disputadas em ambientes quentes.

\section{Efeitos Ergolíticos}

Kreider et al. apontam como principais efeitos ergolíticos citados na literatura: aumento da tensão muscular e das câimbras, supressão da síntese endógena de creatina, desarranjos gastrointestinais, aumento do risco de problemas hepáticos e renais. Em seu artigo ${ }^{12}$, os autores relatam que o aumento da força e da massa muscular dos atletas devido ao treinamento pode provocar um estresse sobre os ossos e ligamentos, muito embora não tenha sido documentado, até então, nenhum estudo mostrando que o aumento da incidência de lesões tenha ocorrido por causa da suplementação com Cr.

Durante os primeiros dias de suplementação, o armazenamento da Cr ocorre essencialmente nos músculos. Nos dias subsequentes, o excesso é excretado pela urina; por isso, um dos possíveis efeitos colaterais é o estresse renal. Estudo realizado por Mendes e Tirapegui indica que o consumo de $\mathrm{Cr}$ no período de até 10 semanas em doses diárias de até $30 \mathrm{~g}$ não altera a função renal de indivíduos saudáveis ${ }^{11}$. A suplementaçáo diária com doses baixas, de até $1,5 \mathrm{~g}$ durante até 5 anos, também não tem provocado alteraçóes.

Entretanto, é importante alertar que o consumo de forma crônica e com megadosagens poderia 
potencialmente produzir algum dano renal. Além disso, esse produto não deve ser utilizado por indivíduos com doenças renais ou por aqueles com risco potencial de disfunçáo renal, como diabéticos, hipertensos e pessoas com taxa de filtração glomerular reduzida ${ }^{7}$. Nesses casos, seria fundamental um acompanhamento médico.

Também tem sido sugerido que a suplementação com $\mathrm{Cr}$ poderia suprimir a síntese endógena. Estudos relatam que essa situaçáo pode ser revertida quando a suplementação é suspensa ${ }^{9,17}$. Um período de 4 semanas após a interrupção do consumo de creatina seria suficiente para que o conteúdo muscular desta substância e da PCr voltem aos níveis normais ${ }^{9,12}$.

A falta de evidências de que o consumo de creatina possa produzir algum dano à integridade física do consumidor é, provavelmente, uma das razões para que esse produto não tenha sido inserido como substância dopante na World Anti-Doping Agency ${ }^{36}$. Contudo, é importante ter cautela em seu consumo, que deve ser avaliado por profissionais do assunto, como médicos e nutricionistas, além de realizar check-ups regulares para monitorar alguma disfunção que possa aparecer. Deve-se ter cuidado também com a pureza do produto utilizado, visto que a composição nutricional não é assegurada em algumas preparaçóes ${ }^{7}$. Tem-se conhecimento de que muitos produtos são importados de forma clandestina, sendo produtos sem o menor controle de qualidade, podendo, assim, estar adicionados de outros produtos, como esteroides anabólicos, o que levaria, por exemplo, a casos de doping involuntário.

\section{Conclusão}

As evidências apontam que a creatina pode ser um auxílio ergogênico eficiente e seguro, principalmente em atividades que exigem força e alta intensidade, podendo ser utilizada também para aumento de massa corporal. Entretanto, ainda são necessários estudos mais conclusivos sobre outros possíveis efeitos, como redução da acidez muscular e termorregulação. Estudos sobre prevalência de consumo apontam a creatina como um dos recursos ergogênicos mais consumidos, sendo mais comumente encontrada na forma de pó e como monoidrato de creatina.

\section{Referências}

1. Hernandez AJ, Nahas RM. Modificaçôes dietéticas, reposição hídrica, suplementos alimentares e drogas: comprovação de ação ergogênica e potenciais riscos para a saúde. Rev Bras Med Esport. 2009;15(3):3-12.

2. Pereira LP. Utilização de recursos ergogênicos nutricionais e/ou farmacológicos em uma academia da cidade de Barra do Piraí, RJ. Rev Bras Nut Esport. 2014;8(43):58-64.
3. Silva AA, Marins JCB. Consumo e nível de conhecimento sobre recursos ergogênicos em atletas. Biosci J. 2013;29(4):1038-48.

4. Andrade LA, Braz VG, Nunes APO, Velutto JN, Mendes RR. Consumo de suplementos alimentares por clientes de uma clínica de nutrição esportiva de São Paulo. R Bras Ci e Mov. 2012;20(3):27-36.

5. Cooper R, Naclerio F, Allgrove J, Jimenez A. Creatine supplememntation with specific view to exercise/sports performance: an update. JISSN. 2012;9(33):1-11.

6. Gualano B, Roschel H, Lancha-Jr H, Brightbill CE, Rawson ES. In sickness and in health: the widespread application of creatine supplementation. Amino Acids. 2012;43:519-29.

7. Poortmans JR, Rawson ES, Burke LM, Stear SJ, Castell LM. A-Z of nutricional supplements: dietary supplements, sports nutrition foods and ergogenic aids for health and performance Part 11. Br J Sports Med. 2010;44:765-66.

8. Tarnopolsky MA. Caffeine and creatine use in sports. Ann Nutr Metab. 2010;57(suppl. 2):1-8.

9. Peralta J, Amancio OMS. A creatina como suplemento ergogênico para atletas. Rev Nutr. 2002;15(1):83-93.

10. Fontana KE, Casal HMV, Baldissera V. Creatina como suplemento ergogênico. Rev Digital Buenos Aires [Internet]. 2003 [citado em: 17 dez. 2013];9(60). Disponível em: http://www.efdeportes.com/efd60/creatina.htm

11. Mendes RR, Tirapegui J. Creatina: o suplemento nutricional para a atividade física: conceitos atuais. Arch Latinoam Nutr. 2002;52(2):117-27.

12. Kreider RB, et al. Effects of creatine supplementation on body composition, strength, and sprint performance. Med Sci Sports Exerc. 1998;30(1):73-82.

13. Rawson E, Venezia AC. Use of creatine in the elderly and evidence for effects on cognitive function in young and old. Amino Acids. 2011;40:1349-62.

14. Jäger R, Purpura M, Shao A, Inoue T, Kreider RB. Analysis of the efficacy, safety, and regulatory status of novel forms of creatine. Amino Acids. 2011;40:1369-83.

15. Williams MH, Kreider RB, Branch JB. Creatina [Internet]. São Paulo: Manole; 2000 [citado em: 07 ago. 2012]. Disponível em: http://books.google.com.br/ books?hl=pt-BR\&lr=\&id=PPA_y1_fSG8C\&oi=fnd \&p$\mathrm{g}=\mathrm{PR} 9 \& \mathrm{dq}=$ creatina $+\mathrm{e}+$ reten $\% \mathrm{C} 3 \% \mathrm{~A} 7 \% \mathrm{C} 3 \% \mathrm{~A} 3 \mathrm{o}+-$ $\mathrm{de}+1 \% \mathrm{C} 3 \%$ ADquido $\&$ ots $=\mathrm{b} 17 \mathrm{vC} 83 \mathrm{Rys} \& \mathrm{sig}=2 \mathrm{xoT}-$ mz9N9nlPQa3Iy6UGfFH0djs\#v=onepage $\& \mathrm{q}=$ creatina $\% 20$ e $\% 20$ reten $\%$ C3\%A7\%C3\%A3o\%20de\%20 $1 \% \mathrm{C} 3 \% \mathrm{ADquido} \& \mathrm{f}=$ false.

16. American college of sports medicine. ACSM's Guidelines for exercise testing and prescription [Internet]. 2009 [citado em: 24 nov. 2013]. $8^{\text {a }}$ ed. Disponível em: http://pt.scribd. com/doc/39307549/Acsm-s-Gdlns-Ex-Test-Prescrp-8ed.

17. Hultman E, Soderlund K, Timmons JA, Cederblad G, Greenhaff PL. Muscle creatine loading in men. J Appl Physiol. 1996:232-37. 
18. Balson PD, Soderlund K, Ekblom B. Creatine in humans with special reference to creatine supplementation. Sports Med. 1994;18(4):268-80.

19. Greenhaff PL, Bodin K, Soderlund K, Hultman E. Effect of oral creatine supplementation on skeletal muscle phosphocreatine resynthesis. Am J Physiol. 1994;266(5):725-30.

20. Mujika I, Chatard JC, Lacoste L, Barale F, Geyssant A. Creatine supplementation does not improve sprint performance in competitive swimmers. Med Sci Sports Exercise. 1996;28(11):1435-40.

21. Yquel RJ, Arsac LM, Thiaudiere E, Canioni P, Manier G. Effect of creatine supplementation on phosphocreatine resynthesis, inorganic phosphate accumulation and $\mathrm{pH}$ during intermittent maximal exercise. J Sports Sci. 2001;20(5):427-37.

22. Maughan RJ. Nutritional ergogenic aids and exercise performance. Nut Res Rev. 1999;12:255-80.

23. Ziegenfuss TN, Lowery LM, Lemon PWR. Acute fluid volume changes in men during three days of creatine supplementation. J Exerc Physiol Online [Internet]. 1998 [citado em: 12 out. 2012];1(3):1-10. Disponível em: http://www. asep.org/asep/asep/jan13d.htm

24. Branch JD, Schuarz WD, Lunen BD. Effect of creatine supplementation on cycle ergometer exercise in hyperthermic environment. J of Strength and Cond Reserch. 2007;21(1):57-61.

25. Jagim AR et al. A buffered form of creatine does not promote greater changes in muscle creatine content, body composition, or training adaptations than creatine monohydrate. J Int Soc Sports Nutr. 2012;9(43).

26. Olsen S. Creatine supplementation augments the increase in satellite cell and myonuclei number in human skeletal muscle induced by strength training. J Physiol. 2006;573(2):525-34.

27. Souza Júnior TP, Dubas JP, Pereira B, De Oliveira PR. Suplementação com creatina e exercício físico. Rev Trein Desp. 2007;8(1):65-70.

28. Haussinger D et al. Estado de hidratação celular: um determinante importante do catabolismo proteico na saúde e na doença. Lancet. 1993;341:1330-2.

29. Hunger MS, Prestes J, Leite RD, Pereira GB, Cavaglieri CR. Efeitos de diferentes doses de suplementação de creatina sobre a composição corporal e força máxima dinâmica. Rev Educ Fís. 2009;20:251-8.

30. Batista JMA, Bravo YJ, Costa EM, De Paula RRR, Araújo AFM, Cunha RM. Suplementação de creatina e treinamento de força: alteraçóes antropométricas e na resultante força máxima. Rev Eletrônica Saúde e Ciência. 2010.

31. Donatto F, Prestes J, Silva FG, Capra E, Navarro F. Efeitos da suplementação aguda de creatina sobre parâmetros de força e composição corporal de praticantes de musculação. Rev Bras Nut Esport. 2007;1(2):38-44.

32. Dalbo VJ, Roberts MD, Stout JR, Kerksick CM. Putting to rest the myth of creatine supplementation leading to muscle cramps and dehydration. Br J Sports Med. 2008;42:567-73.

33. Wright GA, Grandiean PW, Pascoe DD. The effects of creatine loading on thermoregulation and intermittent sprint exercise performance in a hot humid environment. J of Strenght and Cond Reserch. 2007;21(3):655-60.

34. Mendel RW, Blegen M, Cheatham C, Antonio J, Ziegenfuss T. Effects of creatine on thermoregulatory responses while exercising in the heat. Nutrition. 2005;21(3):301-7.

35. Lopez RM, Casa DJ, McDermott BP, Ganio MS, Armstrong LE, Maresh CM. Does creatine supplementation hinder exercise heat tolerance or hydration status? A systematic review with meta-analyses. J of Athletic Training. 2009; 44(2):215-23.

36. Carvalho APPF, Molina GE, Fontana KE. Suplementação com creatina associada ao treinamento resistido não altera as funçôes renal e hepática. Rev Bras Med Esporte [Internet]. 2011 [citado em: 11 jun. 2012];17(4). Disponível em: http://www.scielo.br/pdf/rbme/v17n4/v17n4a04.pdf

37. Pimenta MG, Lopes AC. Consumo de suplementos nutricionais por praticantes de atividade física de academias de ginástica de Cascavel-PR. Simpósio Celafiscs; 2007.

38. Alencar et al. Consumo de suplementos alimentares por praticantes de musculação nas academias da cidade de OuricuriPE. EFDesportes [Internet] 2010 [citado em: 20 dez. 2013]. Disponível em: http://www.efdeportes.com/efd151/consumo-de-suplementos-alimentares-nas-academias.htm

39. Gomes RML. Consumo de suplementos alimentares em frequentadores de ginásio na cidade de Coimbra [Trabalho de conclusão de curso]. Coimbra: Universidade de Coimbra, Faculdade de Medicina; 2010.

40. Pedrosa OP, Silva AC da, Pinho ST de. Utilização de suplementos nutricionais por praticantes de musculação em academias da cidade de Porto Velho Rondônia. Anais da Semana Educa. 2011;1(1).

41. Domingues SF, Marins JCB. Utilização de recursos ergogênicos e suplementos alimentares por praticantes de musculação em Belo Horizonte-MG. Fit Perf J. 2007;6(4):218-26.

42. Chilibeck PD, Magnus C, Anderson M. Effect of in-season creatine supplementation on body composition and performance in rugby union football players. Appl Physiol Nutr Metab. 2007;32(6):1052-7.

43. Cribb PJ, Williams AD, Stathis CG, Carey MF, Hayes A. Effects of whey isolate, creatine, and resistance training on muscle hypertrophy. Med Sci Sports Exer. 2007;39:298-307.

44. Souza Júnior TP, Dubas JP, Pereira B, De Oliveira PR. Suplementação de creatina e treinamento de força: alteraçôes na resultante de força máxima dinâmica e variáveis antropométricas em universitários submetidos a oito semanas de treinamento de força (hipertrofia). Rev Bras Med Esporte. 2007;13(5):303-9.

45. Easton C, Turner S, Pitsiladis YP. Creatine and glycerol hyperhydration in trained subjects before exercise in the heat. Int J Sport Nutr Exerc Metab. 2007;17:70-91. 